\title{
İnsansız Hava Araçlarının Ormanlık Alanlardaki Karayolu Projelerinde Kullanımı
}

\author{
Use of Unmanned Aerial Vehicles in Highway Projects in Forest Areas
}

\author{
Yağmur FIDANCI* ${ }^{\text {1,a }}$, Hakan KARABÖRK ${ }^{2, b}$ \\ ${ }^{1}$ Adlyaman Üniversitesi, Kahta Meslek Yüksekokulu, Kahta, 02400, Adiyaman \\ ${ }^{2}$ Konya Teknik Üniversitesi, Mühendislik ve Doğa Bilimleri Fakültesi, Harita Mühendisliği Bölümü, 42250, Selçuklu, Konya
}

• Geliş tarihi / Received: 08.01.2019 • Düzeltilerek geliş tarihi / Received in revised form: 04.03.2019 • Kabul tarihi / Accepted: 12.03.2019

\begin{abstract}
$\ddot{O ̈ z}$
İnsansız hava araçlarının (IHA) kullanımı, geliștirilen yazılım ve donanım bileșenleri ile günümüzdeki mühendislik uygulamalarında oldukça yaygınlaşmıştır. Farklı yükseklik ve hızlarda uçuş imkânı sağlayan İHA’ların, yüksek çözünürlüklü ve farklı türdeki kameraların kullanımına imkân vermesi ile bazı fotogrametrik sorunlar ortadan kaldırılmıştır. Bu gelişmelerle birlikte, İHA tekniğiyle yüksek doğrulukla sayısal arazi modeli (SAM) üretmek mümkün olabilmektedir. Bu çalışma, ormanlık alanlarda insansız hava aracı görüntülerinden üretilen verilerin karayolu projelerinde kullanılabilirliğini araştırmak amacıyla gerçekleştirilmiştir. Bu doğrultuda yersel yöntem ve İHA ile üretilen veriler hacim miktarları ve yükseklik bilgileri yönünden kıyaslanmıştır. Çalışma alanı olarak ağaçlık yapıda, yaklaşık 800 metre uzunluğunda, 300 metre genişliğinde bir karayolu koridoru seçilmiştir. İnsansız hava aracı ile farklı yükseklikte ve bindirme oranlarında dört adet uçuş gerçekleştirilerek görüntüler elde edilmiştir. Yer kontrol noktaları ve arazi detay noktalarının konumları GNSS cihazı kullanılarak klasik RTK yöntemi ile belirlenmiştir. Görüntüler Pix4D ve Agisoft PhotoScan Professional yazılımlarında farklı sayıda yer kontrol noktası (YKN) ile işlenmiş ve SAM üretilmiştir. Yer kontrol noktalarının yer işaretleme sonuçları ve hata miktarları, yersel ve İHA yöntemiyle üretilmiş detay noktalarının konumları ve hesaplanan toprak işi miktarları karşılaştıılmıştır. Karşılaştırma sonucunda İHA ve yersel yöntemle hesaplanan toprak işi miktarındaki farklar maksimum $\% 3.5$ ve minimum $\% 0.6$, noktaların yükseklikleri arasındaki farklar $12.9 \mathrm{~cm}$ ile $15.9 \mathrm{~cm}$ olarak elde edilmiştir.
\end{abstract}

Anahtar kelimeler: İnsansız Hava Aracı, Karayolu Projesi, Sayısal Yükseklik Modeli, Toprak İşi Hacim Hesabı

\begin{abstract}
Today, using unmanned aerial vehicles (UAVs) has become pretty widespread in engineering applications with software and hardware components that have been developed. Some photogrammetric problems have been eliminated due to the use of high resolution and different camera types by the UAVs that provide flight at different heights and speeds. With these developments, it is possible to produce SAM with high accuracy with UAV technique. This study has been carried out to investigate the usability of unmanned aerial vehicles in highway projects in forested areas. In this direction, the data obtained by the ground method and UAV have been compared in terms of volume quantities and elevation information. As a working area, a wooded highway corridor of about 800 meters in length and 300 meters in width has been chosen. Images have been taken by performing 4 flights at different heights and different overlay rates with unmanned aerial vehicle. The coordinates of ground control points and terrain detail points have been determined by the classical RTK method using the GNSS device. The images have been processed with a different number of ground control points (GCP) in the Pix4D and Agisoft PhotoScan software and the digital terrain models (DTM) have been produced. Location marking results and error amounts of ground control points, calculated soil work and the location of ground points produced by ground measurement technique and UAV method have been compared. As a result, the difference in the amount of soil work has been maximum $3.5 \%$ and the minimum has been $0.6 \%$, and the differences between the heights of the points have been $12.9 \mathrm{~cm}$ and $15.9 \mathrm{~cm}$.
\end{abstract}

Keywords: Unmanned Aerial Vehicle, Highway Project, Digital Terrain Model, Volume Account

\footnotetext{
*a Yağmur FIDANCI, yates@adiyaman.edu.tr, Tel:(0416) 725 8150-51 dâhili: (1197); orcid.org/0000-0001-8701-1463

${ }^{\mathrm{b}}$ orcid.org/0000-0001-7387-7004
} 


\section{Giriş}

İnsansız Hava Araçlarının (İHA) kullanımı; veri toplama ve değerlendirme bileşenlerinin teknolojik gelişmeler doğrultusunda maliyetlerin azalması ve kullanılabilirliğinin artışı dolayısıyla sivil anlamda da yaygınlaşmıştır. İnsansız hava araçları kullanılarak, ormancılık alanında (Menteşoğlu ve İnan, 2016; Akgül vd., 2016), otomatik ağaç tespitinde (Gürbüz ve Türker, 2017), arkeolojik dokümantasyonda (Avdan vd., 2014), heyelan karakterizasyonu modellenmesinde (Carvajal vd., 2011), sayısal yüzey ve arazi modeli doğruluğunun araştırılmasında (Haarbrink ve Eisenbeiss, 2008; Uysal ve Toprak, 2015), ortofoto haritaların doğruluk analizinde (Yılmaz vd., 2013) vb. birçok alanda çalışmalar gerçekleştirilmiştir.

Sayısal arazi modeli (SAM-DTM), zeminin sürekli yüzeyinin, rastgele bir koordinat alanında bilinen $\mathrm{X}, \mathrm{Y}, \mathrm{Z}$ koordinatlarına sahip çok sayıda seçilmiş nokta ile istatistiksel bir temsilidir (Miller ve Laflamme, 1958). Sayısal arazi modeli, yükseklik kavramı yanında diğer coğrafi unsurları ve nehirler, sırt çizgileri, kırılma çizgileri vb. doğal özellikleri de modele dahil etmeye çalışır ( $\mathrm{Li}, 1990)$. Ulaşım sistemlerinde, projelendirme ve uygulama aşamalarında, güzergâh tespiti, hacim ve maliyet hesapları gibi uygulamalarda Sayısal Arazi Modeline ihtiyaç duyulmaktadır. Bu nedenle SAM doğruluğu oluşturulmasında kullanılan yöntem ve teknikler karayolu projelerinde önem taşımaktadır.

Ulaşım sistemlerinde ön proje, kesin proje ve etüt aşamalarında, hacim hesabı işlerinde kullanılmak üzere harita üretimine ihtiyaç duyulmaktadır. Klasik yöntemlerle gerçekleştirilen haritalama işlemi işgücü ve zaman açısından oldukça maliyetlidir. Ayrıca doğal zemin üzerinde istenen sıklıkta veri elde etmek, zorlu ve tehlikeli arazi koşullarında erişim sağlamak her zaman mümkün olmamaktadır. Ancak geliştirilen fotogrametrik teknikler, insansız hava araçları ve algılayıcı teknolojileri ile veri toplama, işleme ve değerlendirme klasik yöntemlere kıyasla daha az işgücü gerektirirken maliyet ve zamandan tasarruf sağlamak mümkündür.

Ulaşım projelerinde insansız hava aracı kullanımına ilişkin oldukça az sayıda çalışma bulunmaktadır. Bununla birlikte yersel teknikle üretilmiş verilerin İHA verilerine kıyası, hacim miktarı karşılaştırması (Tercan, 2017), kullanılan yer kontrol noktasi sayısinın hacim hesabina etkisinin araştırılması (Erdoğan, 2016) şeklinde gerçekleştirilmiştir. Bir başka uygulamada karayolu çalışma alanında toprak yığınlarına ait hacimler incelenmiştir (Siebert ve Teizer, 2014).

$\mathrm{Bu}$ çalışmada, ormanlık arazi yapısına sahip alanlarda insansız hava aracı (IHA) verilerinin doğruluğunu ve karayolu projesi uygulamalarında kullanılabilirliğini incelemek amaçlanmıştır. Literatürde insansız hava aracı görüntülerinden üretilmiş verilerin doğruluğu, yer kontrol noktalarının karesel ortalama hatası ya da hacim doğruluğu açısından irdelenmiştir. Bu çalışmada ise İHA ve yersel yöntemle üretilen hacim miktarları karşış̧̧ııılırken üretilen nokta sayısının hacim doğruluğuna etkisi, yükseklik farkları, farklı uçuş yüksekliği ve bindirme oranlarının konum doğruluğuna etkisi araştırılmıştır. Elde edilmiş insansız hava aracı görüntüleri ile yüksek doğrulukta 3 Boyutlu (3B) nokta bulutu üretilmiştir. Çalışma alanının ormanlı yapıda olması nedeniyle Agisoft PhotoScan yazılımında maksimum açı, maksimum mesafe ve hücre boyutu gibi siniflandirma parametreleri belirlenerek nokta bulutu sınıflandırılmış, sayısal arazi modeli üretilmiş ve toprak işi miktarları yüksek doğrulukla hesaplanmıştır. Çalışma; ormanlık arazi yapısına sahip alanlardaki karayolu projelerinde İHA kullanımı için önemli bir altlık oluşturacaktır.

\section{Materyal ve Yöntem}

\subsection{Uygulama Alant}

$\mathrm{Bu}$ çalışmada Bolu-Seben İl Yolu arasında, yaklaşık 300 metre genişliğinde ve 800 metre uzunluğunda bir koridoru kapsayan kısım uygulama alanı olarak belirlenmiştir. Bölge, ağaçlık ve dağlık yapıda olması göz önünde bulundurularak seçilmiştir (Şekil 1).

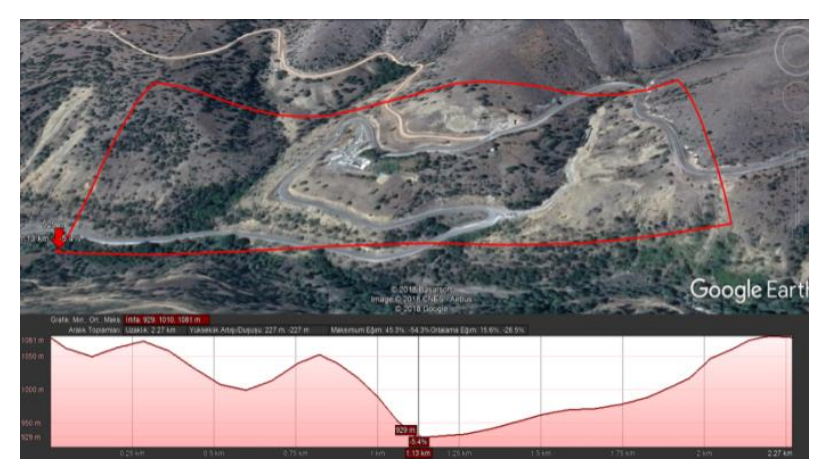

Şekil 1. Çalışma Alanı 


\subsection{Insansız, Hava Aracı}

Çalışmada Sayısal Arazi Modeli ve ortofoto üretimi için kullanılacak İHA (İnsansız Hava Aracı) görüntüleri DJI Phantom 4 Pro cihazı ile elde edilmiştir (Şekil 2).

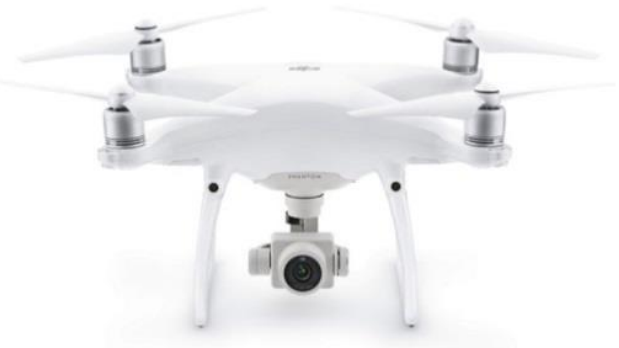

Şekil 2. DJI Phantom 4 Pro insansız hava aracı

DJI Phantom 4 Pro cihazı pil ve pervaneler dahil 1388 gr ağırlığında olup, 6000 metre irtifaya kadar çıkabilme ve maksimum 30 dakikaya kadar uçuş kapasitesine sahiptir. Uydu konumlama sistemi olarak GPS/GLONASS mevcuttur. Kamera olarak cihaza sabitlenmiş $20 \mathrm{MP}, \mathrm{f} / 2,8-$ f/11 açıklığa sahip diyafram, 8-1/2000 sn. mekanik deklanşör ve $8-1 / 8000$ elektronik deklanşör hızına sahip, 1 inç CMOS algılayıcıya sahiptir.

\subsection{Yer Kontrol Noktalarının Ölçümleri}

İnsansiz hava arac1 görüntülerinin dengelenmesinde kullanılacak 21 adet yer kontrol noktası belirlenmiştir. Yer kontrol noktaları, çalışma alanı içerisinde homojen olarak dağılmış ve arazinin kritik noktaları da gözetilerek zemin ile zit renkte işaretlenmiştir (Şekil 3).

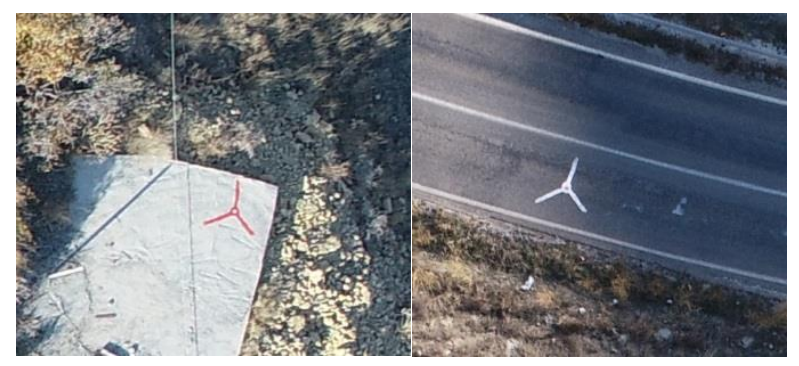

Şekil 3. Yer kontrol noktaları

Yer kontrol noktalarının konumları Javad marka Triumph-1 model GNSS cihazı ile ölçülmüştür (Şekil 4). Ölçme işlemi Klasik RTK(Real Time Kinematic) yöntemi kullanılarak gerçekleştirilmiş olup cihaz yatayda $1 \mathrm{~cm}+1 \mathrm{ppm}$, düşeyde $1.5+1$ ppm RTK doğruluğuna sahiptir.

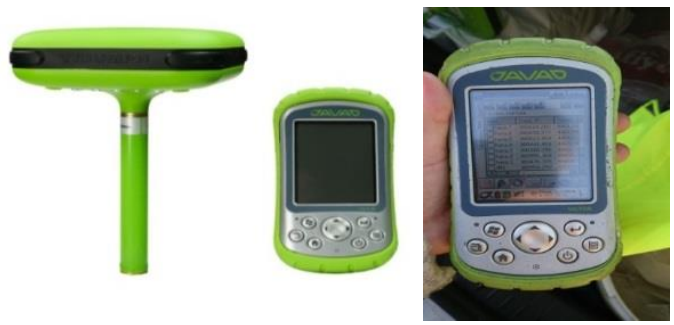

Şekil 4. Javad Triumph-1 GNSS cihazı

$\mathrm{Bu}$ çalışmada yersel ölçülerden ve İHA görüntülerinden faydalanılmıştır. Yersel ölçüm işlemleri GNSS cihazı ile Klasik RTK yöntemi kullanılarak yapılmış ve arazinin topografik yüzeyi 1907 nokta ile temsil edilmiştir. RTK yöntemiyle gerçekleştirilen ölçümler doğru kabul edilip karşlaştırmalar bu değerlere göre gerçekleştirilmiştir.

İnsansız hava aracı ile farklı yükseklik ve bindirme oranında görüntüler alınmıştır. Görüntülerden üretilen veriler ile yersel yöntemle üretilen veriler karşılaştırılarak, uçuş yüksekliği ve bindirme oranının doğruluğa etkisini araştırılmıştır. Uçuş işlemi için Pix4DCapture yazılımı kullanılarak uçuş yüksekliği, bindirme oranları, uçuş hızı ve görüntüleme alanının tanımlandığ1 dört ayrı uçuş planı hazırlanmıştır (Şekil 5,6,7,8).

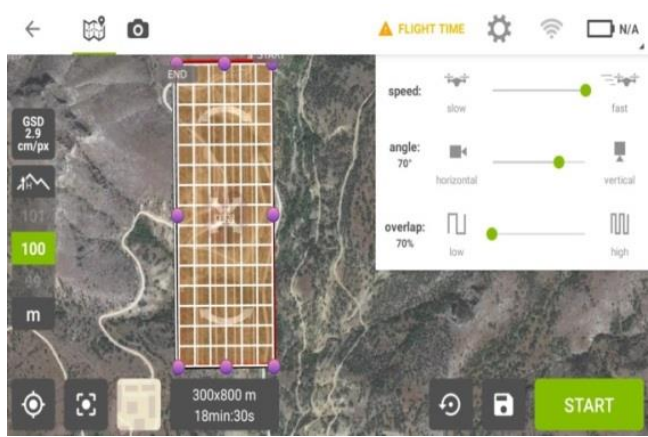

Şekil 5. $100 \mathrm{~m}$ yükseklikte enine ve boyuna $\% 70$ bindirme oranı ile uçuş planı

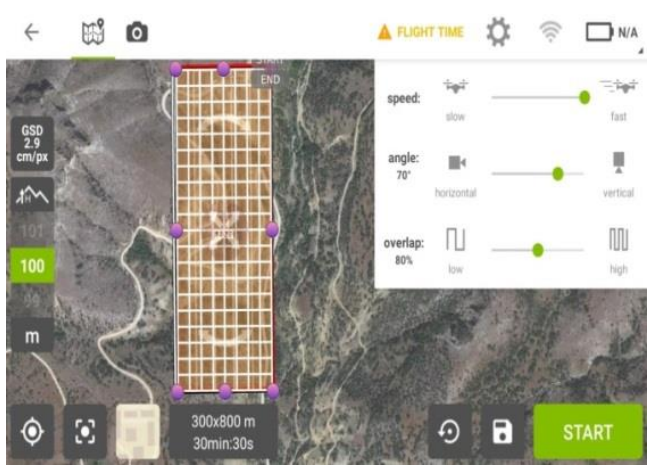

Şekil 6. 100 m yükseklikte enine ve boyuna $\% 80$ bindirme oranı ile uçuş planı 


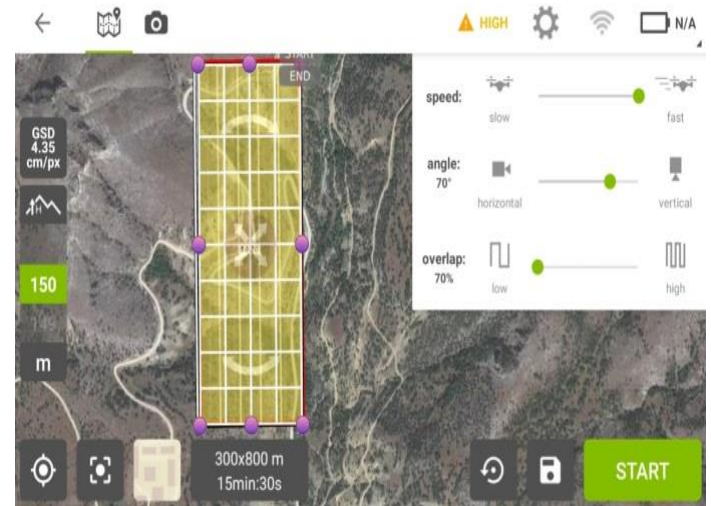

Şekil 7. $150 \mathrm{~m}$ yükseklikte enine ve boyuna $\% 70$ bindirme oranı ile uçuş planı

Uçuşlar sırasıyla; 100 metre yükseklikte $\% 70$ enine ve boyuna bindirme oran1 ile, 100 metre yükseklikte $\% 80$ enine ve boyuna bindirme oran1 ile, 150 metre yükseklikte $\% 70$ enine ve boyuna

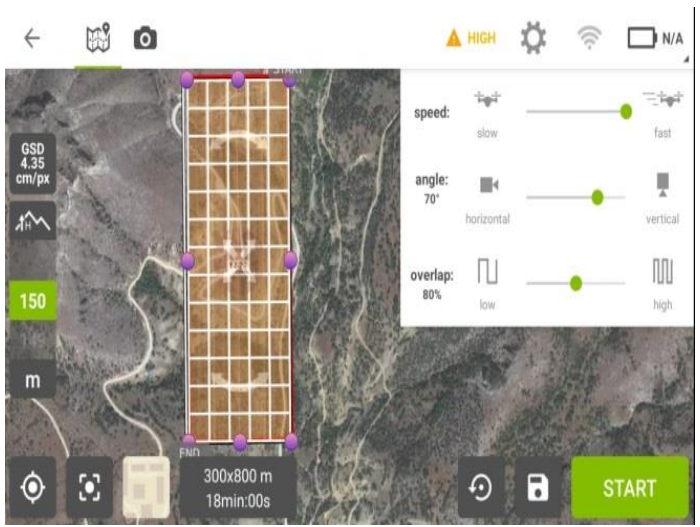

Şekil 8. 150 m yükseklikte enine ve boyuna $\% 80$ bindirme oranı ile uçuş planı

bindirme oranı ile, 150 metre yükseklikte $\% 80$ enine ve boyuna bindirme oranı ile planlanmış olup uçuş bilgileri Tablo 1'de verilmiştir.

Tablo 1. Uçuş bilgileri

\begin{tabular}{|l|l|l|l|l|}
\hline Uçuş Bilgileri & Uçuş Süresi & Fotoğraf Sayıs1 & Kolon Sayıs1 & Alınan Yol \\
\hline $100 \mathrm{~m}$ yükseklikte $\% 70$ bindirme oranı ile & $18 \mathrm{~d} 30 \mathrm{sn}$ & 347 & 7 & $6311 \mathrm{~m}$ \\
\hline $100 \mathrm{~m}$ yükseklikte $\% 80$ bindirme oranı ile & $30 \mathrm{~d} 30 \mathrm{sn}$ & 435 & 9 & $7730 \mathrm{~m}$ \\
\hline $150 \mathrm{~m}$ yükseklikte $\% 70$ bindirme oranı ile & $15 \mathrm{~d} 30 \mathrm{sn}$ & 167 & 5 & $4715 \mathrm{~m}$ \\
\hline $150 \mathrm{~m}$ yükseklikte $\% 80$ bindirme oranı ile & $18 \mathrm{~d} 00 \mathrm{sn}$ & 296 & 6 & $5516 \mathrm{~m}$ \\
\hline
\end{tabular}

İnsansız hava aracı ile elde edilen görüntüler Pix4D ve Agisoft PhotoScan Professional yazılımları ile değerlendirilmiştir. İlk olarak her iki yazılımda da 11 adet yer kontrol noktas (YKN) görüntülerde işaretlenmiş ve dengelemede kullanılmıştır.10 adet nokta ise üretilen 3B model üzerinde yatay ve düşey doğruluğu kontrol amaçlı olarak kullanılmıştır. İkinci değerlendirme işlemi ise 21 adet yer kontrol noktasi (YKN) görüntülerde işaretlenerek blok dengeleme işlemi gerçekleştirilmiştir. Her bir dengeleme işleminde görüntülerde işaretlenen yer kontrol noktalarına ait hata miktarları Tablo 2 ve 3 'te verilmiştir.

Tablo 2. Pix4D yazılımında yer kontrol noktalarının (YKN) dengeleme sonuçları

\begin{tabular}{|l|l|l|l|l|l|l|l|}
\hline $\begin{array}{l}\text { Kullanılan } \\
\text { YKN Sayıs1 }\end{array}$ & $\begin{array}{l}\text { Uçuş } \\
\text { Yüksekliği }\end{array}$ & $\begin{array}{l}\text { Bindirme } \\
\text { Oranı }\end{array}$ & $\begin{array}{l}\text { KOH } \\
\mathrm{X}(\mathrm{cm})\end{array}$ & $\begin{array}{l}\mathrm{KOH} \\
\mathrm{Y}(\mathrm{cm})\end{array}$ & $\begin{array}{l}\mathrm{KOH} \\
\mathrm{Z}(\mathrm{cm})\end{array}$ & $\begin{array}{l}\text { YÖA (cm/piksel) } \\
\text { Ortomozaik }\end{array}$ & $\begin{array}{l}\text { 3B Nokta } \\
\text { say1s1 }\end{array}$ \\
\hline \multirow{4}{*}{11} & $100 \mathrm{~m}$ & $\% 70$ & 1.1 & 2.1 & 1.8 & $2.85 / 1.12$ & 48078047 \\
\cline { 2 - 8 } & $100 \mathrm{~m}$ & $\% 80$ & 1.2 & 2.4 & 1.3 & $2.80 / 1.10$ & 56041783 \\
\cline { 2 - 8 } & $150 \mathrm{~m}$ & $\% 70$ & 1.4 & 2.7 & 4.9 & $4.20 / 1.65$ & 24802531 \\
\cline { 2 - 8 } & $150 \mathrm{~m}$ & $\% 80$ & 1.3 & 3.1 & 2.5 & $4.21 / 1.66$ & 34655454 \\
\hline \multirow{3}{*}{21} & $100 \mathrm{~m}$ & $\% 70$ & 1.2 & 2.3 & 4.0 & $2.85 / 1.12$ & 48378284 \\
\cline { 2 - 8 } & $100 \mathrm{~m}$ & $\% 80$ & 1.6 & 3.0 & 3.2 & $2.80 / 1.10$ & 55780927 \\
\cline { 2 - 8 } & $150 \mathrm{~m}$ & $\% 70$ & 1.8 & 3.1 & 5.9 & $4.20 / 1.66$ & 24821809 \\
\cline { 2 - 8 } & $150 \mathrm{~m}$ & $\% 80$ & 1.9 & 3.7 & 5.3 & $4.22 / 1.66$ & 33378114 \\
\hline
\end{tabular}


Tablo 3. Agisoft PhotoScan yazılımında yer kontrol noktalarının (YKN) dengeleme sonuçları

\begin{tabular}{|c|c|c|c|c|c|c|c|c|c|}
\hline $\begin{array}{c}\text { Kullanılan } \\
\text { YKN } \\
\text { Say1s1 }\end{array}$ & $\begin{array}{c}\text { Uçuş } \\
\text { Yüksekliği }\end{array}$ & $\begin{array}{c}\text { Bindirme } \\
\text { Oranı }\end{array}$ & $\begin{array}{l}\text { YKN } \\
\text { Say1s1 }\end{array}$ & $\begin{array}{l}\mathrm{KOH} \\
\mathrm{X}(\mathrm{cm})\end{array}$ & $\begin{array}{l}\mathrm{KOH} \\
\mathrm{Y}(\mathrm{cm})\end{array}$ & $\begin{array}{l}\mathrm{KOH} \\
\mathrm{Z}(\mathrm{cm})\end{array}$ & $\begin{array}{c}\text { YÖA } \\
\text { (cm/piksel) } \\
\text { Ortomozaik }\end{array}$ & $\begin{array}{l}\text { 3B Nokta } \\
\text { Sayıs1 }\end{array}$ & $\begin{array}{c}\text { SAM } \\
\text { Çözünürlüğü }\end{array}$ \\
\hline \multirow{4}{*}{11} & $100 \mathrm{~m}$ & $\% 70$ & 11 & 0.9 & 1.6 & 0.4 & 2.82 & 48435041 & 11.3 \\
\hline & $100 \mathrm{~m}$ & $\% 80$ & 11 & 1.0 & 1.8 & 0.6 & 2.75 & 50750077 & 11.0 \\
\hline & $150 \mathrm{~m}$ & $\% 70$ & 11 & 0.9 & 1.7 & 1.0 & 4.13 & 27320510 & 16.5 \\
\hline & $150 \mathrm{~m}$ & $\% 80$ & 11 & 0.9 & 2.1 & 1.1 & 4.13 & 29781013 & 16.5 \\
\hline \multirow{4}{*}{21} & $100 \mathrm{~m}$ & $\% 70$ & 21 & 1.2 & 1.7 & 2.1 & 2.82 & 48417447 & 11.3 \\
\hline & $100 \mathrm{~m}$ & $\% 80$ & 21 & 1.2 & 1.6 & 2.7 & 2.75 & 50756077 & 11.0 \\
\hline & $150 \mathrm{~m}$ & $\% 70$ & 21 & 1.6 & 1.9 & 2.8 & 4.13 & 27514899 & 16.5 \\
\hline & $150 \mathrm{~m}$ & $\% 80$ & 21 & 1.7 & 2.6 & 4.0 & 4.13 & 29780367 & 16.5 \\
\hline
\end{tabular}

Agisoft PhotoScan ve Pix4D yazılımları ile dengeleme işlemi ardından yoğun nokta bulutu üretilmiştir. Agisoft PhotoScan yazılımında üretilen nokta bulutunda siniflandirma parametreleri belirlenmiş ve Şekil 9'da gösterilmiştir. Yoğun nokta bulutu kullanılarak üçgen model, sayısal arazi modeli (Şekil 10,11), sayısal yüzey modeli ve ortofoto harita üretilmiştir.

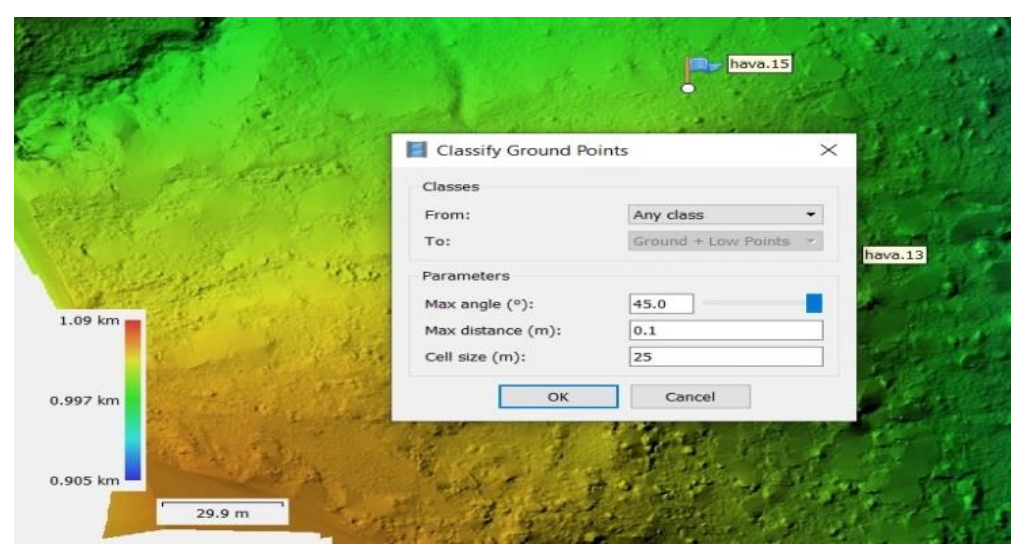

Şekil 9. Agisoft PhotoScan sınıflandırma parametreleri

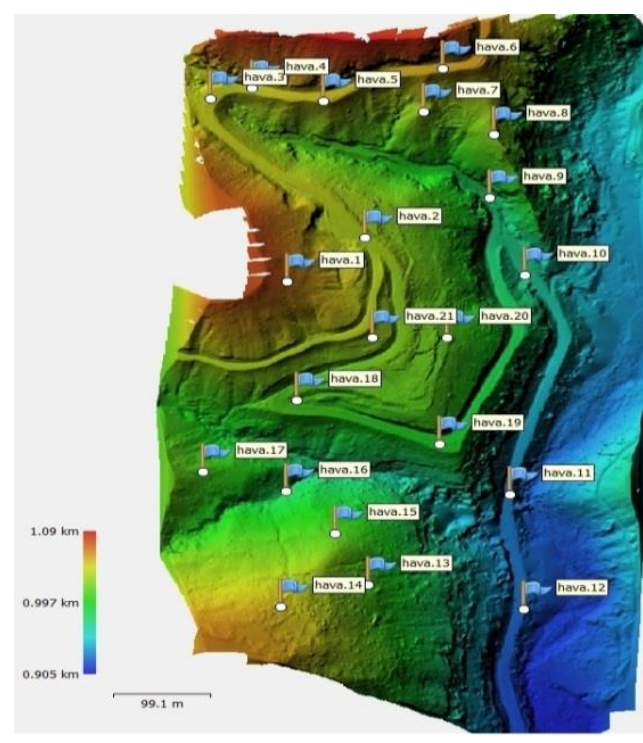

Şekil 10. Agisoft PhotoScan yazılımında sayısal arazi modeli

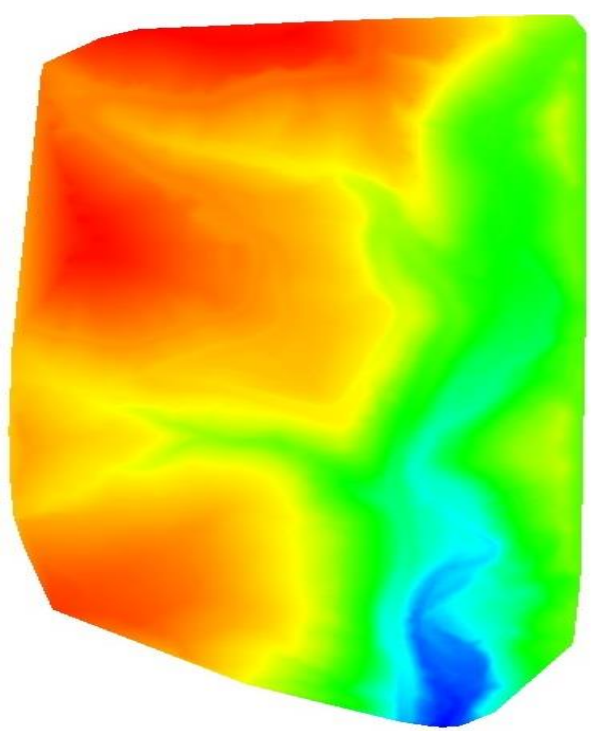

Şekil 11. Pix4Dyazılımında sayısal arazi modeli 
Zeminde işaretli 10 adet yer kontrol noktasının konumları 3B model üzerinden işaretlenerek yersel yöntemle üretilen değerlerle karşılaştırılmış ve sonuçları Tablo 4 ve Tablo 5'te verilmiştir.

Tablo 4. Agisoft PhotoScan yazılımı 3B modeli üzerinden alınan 10 adet yer kontrol noktasının (YKN) karşılaştırma sonuçları

\begin{tabular}{|c|c|c|c|c|c|c|}
\hline \multirow{2}{*}{ N.NO } & \multicolumn{3}{|c|}{$\begin{array}{l}\text { PhotoScan } 100 \mathrm{~m} \text { Yükseklik } \\
\text { \%70 Bindirme oranı }\end{array}$} & \multicolumn{3}{|c|}{$\begin{array}{l}\text { PhotoScan } 100 \mathrm{~m} \text { Yükseklik } \\
\text { \%80 Bindirme oranı }\end{array}$} \\
\hline & $\begin{array}{c}d_{y}(\text { Farklar }) \\
(\mathbf{c m})\end{array}$ & $\begin{array}{c}d_{x}(\text { Farklar }) \\
(\text { cm })\end{array}$ & $\begin{array}{c}\mathrm{d}_{\mathrm{H}}(\text { Farklar }) \\
(\mathrm{cm})\end{array}$ & $\begin{array}{c}d_{y}(\text { Farklar }) \\
(\mathbf{c m})\end{array}$ & $\begin{array}{c}d_{x}(\text { Farklar }) \\
(\mathrm{cm})\end{array}$ & $\begin{array}{c}\mathbf{d}_{\mathrm{H}}(\text { Farklar }) \\
(\mathbf{c m})\end{array}$ \\
\hline Hava.2 & -5.00 & 2.00 & -2.10 & -3.30 & -0.30 & -1.70 \\
\hline Hava.3 & 2.70 & 1.80 & 2.20 & 0.80 & 2.50 & 2.20 \\
\hline Hava.5 & 8.70 & 2.50 & 1.20 & 5.80 & 4.30 & 1.90 \\
\hline Hava.7 & -0.80 & 0.80 & -6.70 & 2.90 & -0.90 & -5.90 \\
\hline Hava.9 & 2.10 & 0.80 & 1.70 & 1.70 & 1.40 & 0.60 \\
\hline Hava.11 & 2.50 & -4.90 & -7.10 & 3.50 & -4.70 & -6.30 \\
\hline Hava.15 & -0.20 & 2.90 & -7.00 & 3.40 & -1.60 & -3.40 \\
\hline Hava.17 & -1.00 & -3.20 & -7.20 & -2.00 & -0.60 & -15.40 \\
\hline Hava.19 & 1.10 & 5.70 & -3.20 & -2.90 & 2.90 & -3.90 \\
\hline Hava.21 & 3.50 & 0.70 & -14.50 & 1.10 & 4.10 & -10.70 \\
\hline $\mathrm{KOH}(\mathrm{cm})$ & 3.66 & 3.01 & 6.56 & 3.06 & 2.79 & 6.82 \\
\hline \multirow{2}{*}{ N.NO } & \multicolumn{3}{|c|}{$\begin{array}{l}\text { PhotoScan } 150 \mathrm{~m} \text { Yükseklik } \\
\text { \%70 Bindirme oranı }\end{array}$} & \multicolumn{3}{|c|}{$\begin{array}{c}\text { PhotoScan } 150 \text { m Yükseklik } \\
\% 80 \text { Bindirme oranı }\end{array}$} \\
\hline & $\begin{array}{c}d_{y}(\text { Farklar }) \\
(\mathbf{c m})\end{array}$ & $\begin{array}{c}d_{x}(\text { Farklar }) \\
(\text { cm })\end{array}$ & $\begin{array}{c}\mathbf{d}_{\mathrm{H}}(\text { Farklar }) \\
(\mathrm{cm})\end{array}$ & $\begin{array}{c}d_{y}(\text { Farklar }) \\
(\mathbf{c m})\end{array}$ & $\begin{array}{c}d_{x}(\text { Farklar }) \\
(\text { cm })\end{array}$ & $\begin{array}{c}\mathbf{d}_{\mathrm{H}}(\text { Farklar }) \\
(\mathbf{c m})\end{array}$ \\
\hline Hava.2 & -5.50 & 0.70 & -7.80 & -3.90 & -0.30 & -5.00 \\
\hline Hava.3 & 2.40 & 5.00 & -2.90 & 4.50 & -0.80 & -9.10 \\
\hline Hava.5 & 7.70 & 8.70 & -0.30 & 7.30 & 6.50 & -0.90 \\
\hline Hava.7 & -2.50 & 1.80 & -14.50 & -0.60 & 3.00 & -3.30 \\
\hline Hava.9 & 5.40 & 1.00 & -2.70 & 2.00 & -1.40 & -14.80 \\
\hline Hava.11 & -8.20 & 1.80 & -12.60 & -7.20 & 5.00 & -12.00 \\
\hline Hava.15 & 1.00 & -1.10 & -9.10 & 4.20 & -2.10 & -12.00 \\
\hline Hava.17 & -3.20 & -0.20 & -18.80 & 0.60 & -2.50 & -11.60 \\
\hline Hava.19 & -1.70 & 0.40 & -5.80 & 2.20 & -2.40 & -7.00 \\
\hline Hava.21 & -0.60 & 4.70 & -9.40 & 2.10 & -1.50 & -11.90 \\
\hline $\mathrm{KOH}(\mathrm{cm})$ & 4.61 & 3.64 & 10.02 & 4.15 & 3.12 & 9.76 \\
\hline
\end{tabular}


Tablo 5. Pix4D yazılımı 3B modeli üzerinden alınan 10 adet yer kontrol noktasının (YKN) karşılaştırma sonuçları

\begin{tabular}{|c|c|c|c|c|c|c|}
\hline \multirow{2}{*}{ N.NO } & \multicolumn{3}{|c|}{$\begin{array}{l}\text { Pix4D } 100 \text { m Yükseklik } \\
\text { \%70 Bindirme oranı }\end{array}$} & \multicolumn{3}{|c|}{$\begin{array}{l}\text { Pix4D } 100 \text { m Yükseklik } \\
\text { \%80 Bindirme oranı }\end{array}$} \\
\hline & $\begin{array}{c}\mathbf{d}_{\mathbf{y}}(\text { Farklar }) \\
(\mathbf{c m})\end{array}$ & $\begin{array}{c}\mathbf{d}_{\mathbf{x}}(\text { Farklar }) \\
(\mathbf{c m})\end{array}$ & $\begin{array}{c}\mathbf{d}_{\mathrm{H}}(\text { Farklar }) \\
(\mathrm{cm})\end{array}$ & $\begin{array}{c}\mathbf{d}_{\mathbf{y}}(\text { Farklar }) \\
(\mathbf{c m})\end{array}$ & $\begin{array}{c}\mathbf{d}_{\mathrm{x}}(\text { Farklar }) \\
(\mathrm{cm})\end{array}$ & $\begin{array}{c}\mathbf{d}_{\mathrm{H}}(\text { Farklar }) \\
(\mathbf{c m})\end{array}$ \\
\hline Hava.2 & -2.60 & 1.70 & -3.30 & -1.60 & 1.70 & -1.30 \\
\hline Hava.3 & -0.40 & 3.80 & -2.80 & 1.60 & 2.80 & -0.80 \\
\hline Hava.5 & 6.40 & 8.30 & 3.70 & 6.40 & 8.30 & 4.70 \\
\hline Hava.7 & -2.80 & 2.10 & -5.70 & 0.20 & 0.10 & -2.70 \\
\hline Hava.9 & -0.80 & 4.90 & 6.10 & -0.80 & 1.90 & 0.10 \\
\hline Hava.11 & -1.50 & -0.40 & -3.20 & -1.50 & -2.40 & -1.20 \\
\hline Hava.15 & 1.20 & 2.00 & -5.70 & -0.80 & -1.00 & -10.70 \\
\hline Hava.17 & -1.90 & -1.60 & -4.30 & -0.90 & -0.60 & -0.30 \\
\hline Hava.19 & 2.60 & 4.40 & -1.60 & -0.40 & 1.40 & 0.40 \\
\hline Hava.21 & 3.60 & 2.90 & -6.20 & 0.60 & 4.90 & 0.80 \\
\hline $\mathrm{KOH}(\mathrm{cm})$ & 2.89 & 3.86 & 4.52 & 2.26 & 3.41 & 3.85 \\
\hline \multirow[t]{2}{*}{ N.NO } & \multicolumn{3}{|c|}{$\begin{array}{l}\text { Pix4D } 150 \text { m Yükseklik } \\
\text { \%70 Bindirme oranı }\end{array}$} & \multicolumn{3}{|c|}{$\begin{array}{l}\text { Pix4D } 150 \text { m Yükseklik } \\
\text { \%80 Bindirme oranı }\end{array}$} \\
\hline & $\begin{array}{c}\mathbf{d}_{\mathrm{y}}(\text { Farklar }) \\
(\mathrm{cm})\end{array}$ & $\begin{array}{c}\mathbf{d}_{\mathbf{x}}(\text { Farklar }) \\
(\mathbf{c m})\end{array}$ & $\begin{array}{c}\mathbf{d}_{\mathrm{H}}(\text { Farklar }) \\
(\mathrm{cm})\end{array}$ & $\begin{array}{c}\mathbf{d}_{\mathbf{y}}(\text { Farklar }) \\
(\mathrm{cm})\end{array}$ & $\begin{array}{c}\mathbf{d}_{\mathrm{x}}(\text { Farklar }) \\
(\mathrm{cm})\end{array}$ & $\begin{array}{c}\mathbf{d}_{\mathrm{H}}(\text { Farklar }) \\
(\mathrm{cm})\end{array}$ \\
\hline Hava.2 & -3.60 & -0.30 & -3.30 & -3.60 & -2.30 & -1.30 \\
\hline Hava.3 & 6.60 & 2.80 & -0.80 & 5.60 & 3.80 & 3.20 \\
\hline Hava.5 & 5.40 & 4.30 & 1.70 & 5.40 & 3.30 & 4.70 \\
\hline Hava.7 & -2.80 & 2.10 & -4.70 & -0.80 & 4.10 & -5.70 \\
\hline Hava.9 & 1.20 & 3.90 & 11.10 & 0.20 & 1.90 & -0.90 \\
\hline Hava.11 & -2.50 & -3.40 & 1.80 & 0.50 & 0.60 & -3.20 \\
\hline Hava.15 & 0.20 & 1.00 & -10.70 & -0.80 & -2.00 & -12.70 \\
\hline Hava.17 & -0.90 & -0.60 & -15.30 & -0.90 & 1.40 & -7.30 \\
\hline Hava.19 & -2.40 & 1.40 & 0.40 & 4.60 & 0.40 & -3.60 \\
\hline Hava.21 & -0.40 & 3.90 & -7.20 & -0.40 & 2.90 & -2.20 \\
\hline KOH $(\mathrm{cm})$ & 3.29 & 2.76 & 7.51 & 3.12 & 2.57 & 5.57 \\
\hline
\end{tabular}

İkinci değerlendirme işleminde iki yazılımda da her bir uçuş için 21 adet yer kontrol noktası ile dengeleme yapılmıştır. Nokta bulutu üretilmiş, sınıflandırma işlemi yapılmış (Şekil 12), üçgen model, sayısal arazi modeli, sayısal yüzey modeli (Şekil 13) ve ortofoto-mozaik (Şekil 14,15) üretilmiştir.

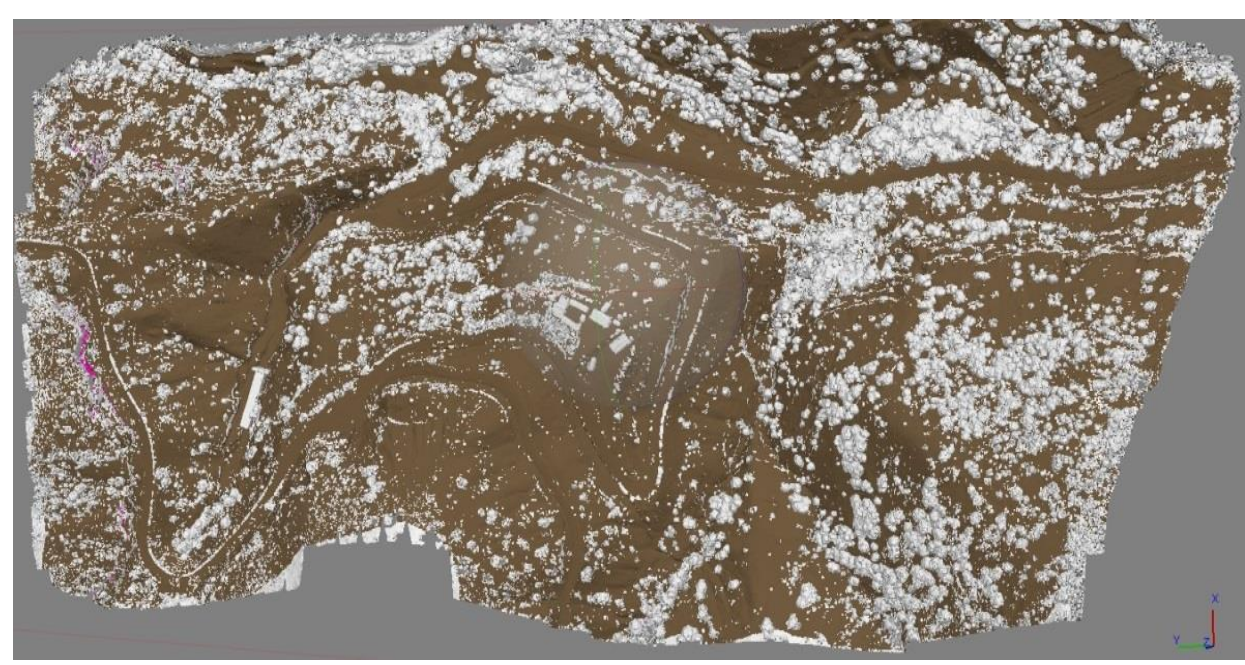

Şekil 12.Agisoft PhotoScan sınıflandırılmış nokta bulutu görünümü 


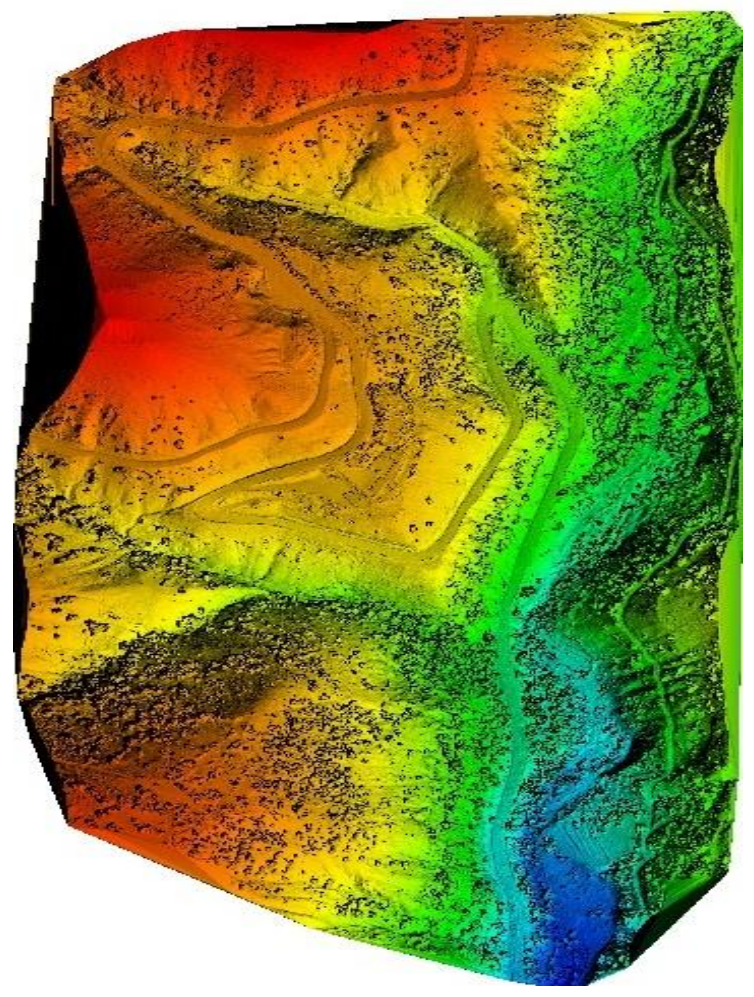

Şekil 13. Pix4D yazılımda sayısal yüzey modeli

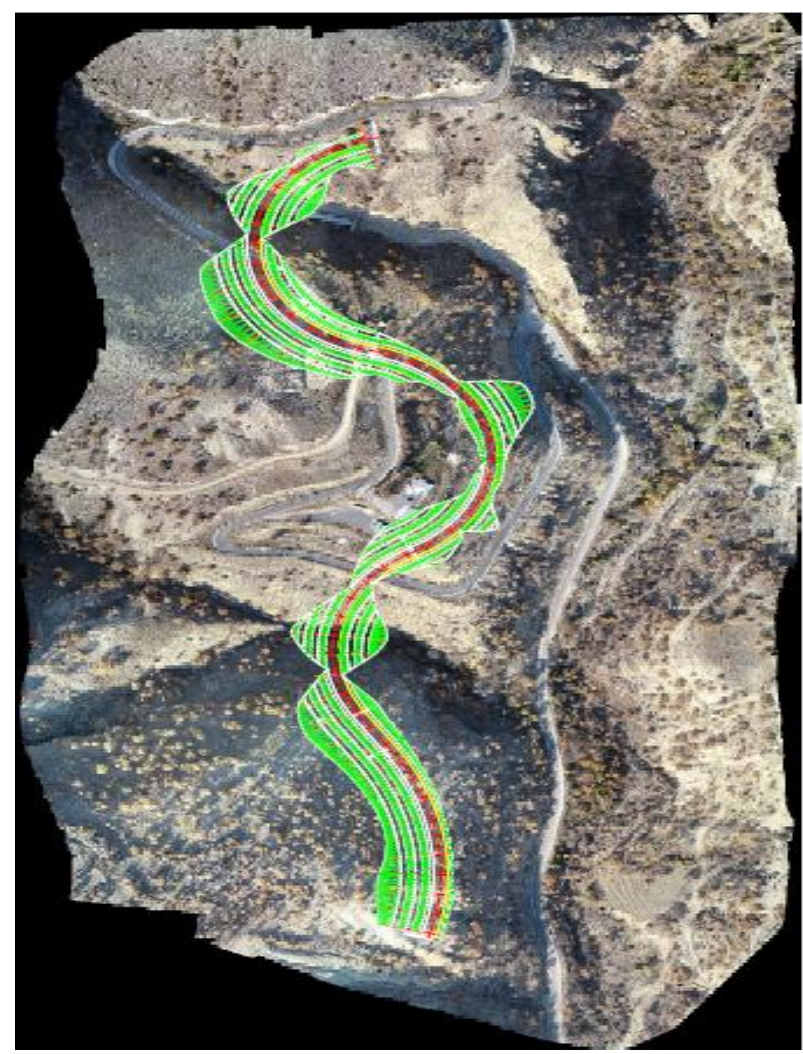

Şekil 15. Ortofoto ve karayolu güzergahı

Yersel yöntemle elde edilmiş noktaların yükseklikleri, Pix4D yazılımında 21 adet YKN

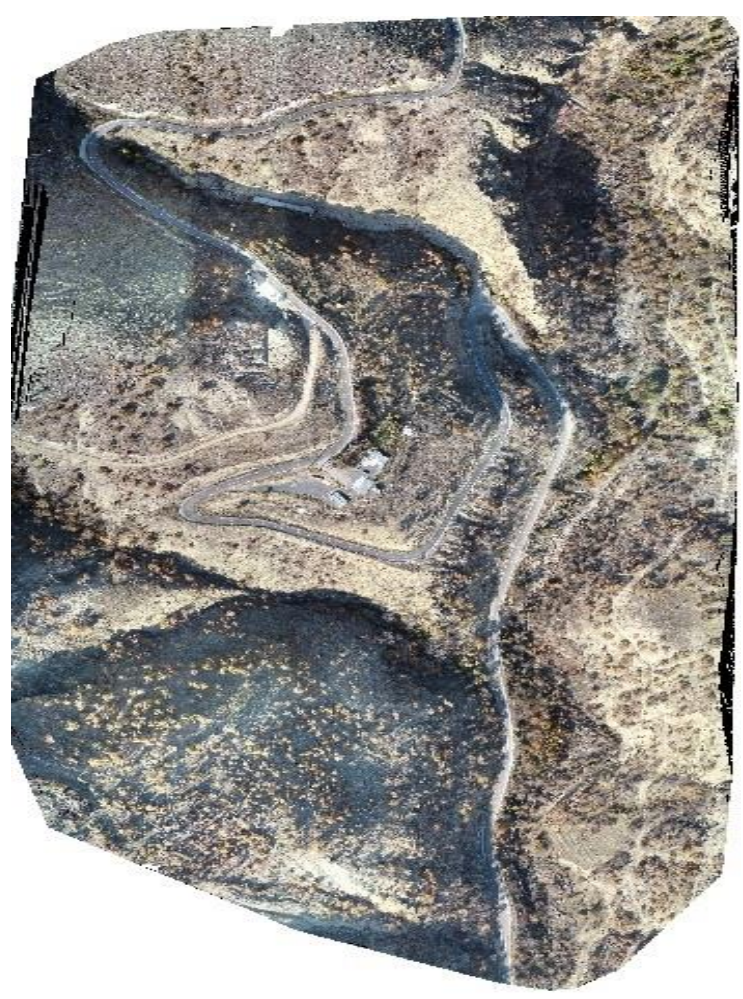

Şekil 14. Pix4D yazılımda ortofoto örneği

kullanılarak üretilen sayısal arazi modellerinin tümünde yataydaki konumuna karşı1lk gelen 1907 noktanın yüksekliği ile karşılaştırılmıştır. 1907 noktaya ait yükseklik verileri Autocad Civil 3D yazılımı kullanılarak, farklı değerlendirmeler sonucunda üretilmiş sayısal arazi modellerinden üretilmiştir. Ek olarak Agisoft PhotoScan yazılımı ile $100 \mathrm{~m}$ yükseklikten enine ve boyuna $\% 80$ bindirme oranı ile elde edilen görüntülere ait sayısal arazi modeli verileri de kıyaslanmıştır. 10 adet YKN ile gerçekleştirilen değerlendirmeden yola çıkarak yatayda kabul edilebilir sonuçlar vermesi nedeniyle karşılaştırma yalnızca yükseklik verileri üzerinden yapılmıştır. Pix4D yazılımı önceki değerlendirmelerde daha doğru sonuçlar verdiğinden bu yazılım verileri kullanılmıştır.1907 noktaya ait yükseklik farklarının karesel ortalama hatası Tablo 6'da verilmiştir.

Tablo 6'da verilen değerler incelendiğinde en iyi sonuç 100 metre yükseklikten $\% 80$ bindirme oranıyla alınan görüntülere ait verilerden elde edilmiştir. Yersel yöntemle ve İHA yöntemi ile üretilen noktalara ait sayısal arazi modeli ile karayolu projesi çakıştırılarak profiller oluşturulmuş ve Şekil 16- Şekil 18 arasında gösterilmiştir. 
Tablo 6. Yersel ölçüm ve İHA görüntülerinden üretilen noktalara ait yükseklik verilerinin karşılaştırılması

\begin{tabular}{|l|l|l|l|l|l|}
\hline & $\begin{array}{c}\text { Pix4D 100 m } \\
\text { Yükseklik \%70 } \\
\text { Bindirme }\end{array}$ & $\begin{array}{c}\text { Pix4D 100 m } \\
\text { Yükseklik \%80 } \\
\text { Bindirme }\end{array}$ & $\begin{array}{c}\text { Pix4D 150 m } \\
\text { Yükseklik \%70 } \\
\text { Bindirme }\end{array}$ & $\begin{array}{c}\text { Pix4D 150 m } \\
\text { Yükseklik \%80 } \\
\text { Bindirme }\end{array}$ & $\begin{array}{c}\text { PhotoScan 100 m } \\
\text { Yükseklik \%80 } \\
\text { Bindirme }\end{array}$ \\
\hline KOH(cm) & 13.0 & 2.9 & 14.2 & 14.5 & 15.9 \\
\hline
\end{tabular}

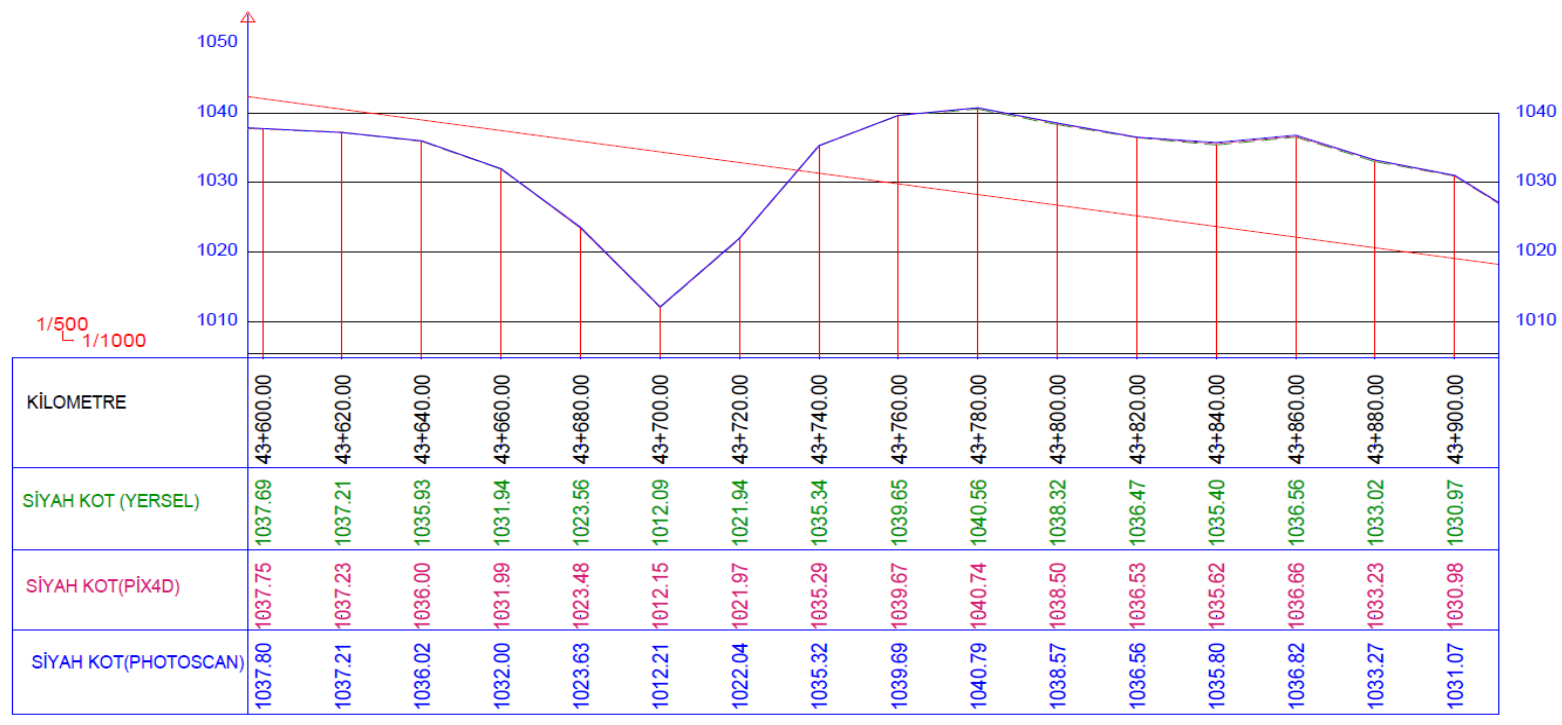

Şekil 16. $43+600.00-43+900.00 \mathrm{Km}$ arası profil

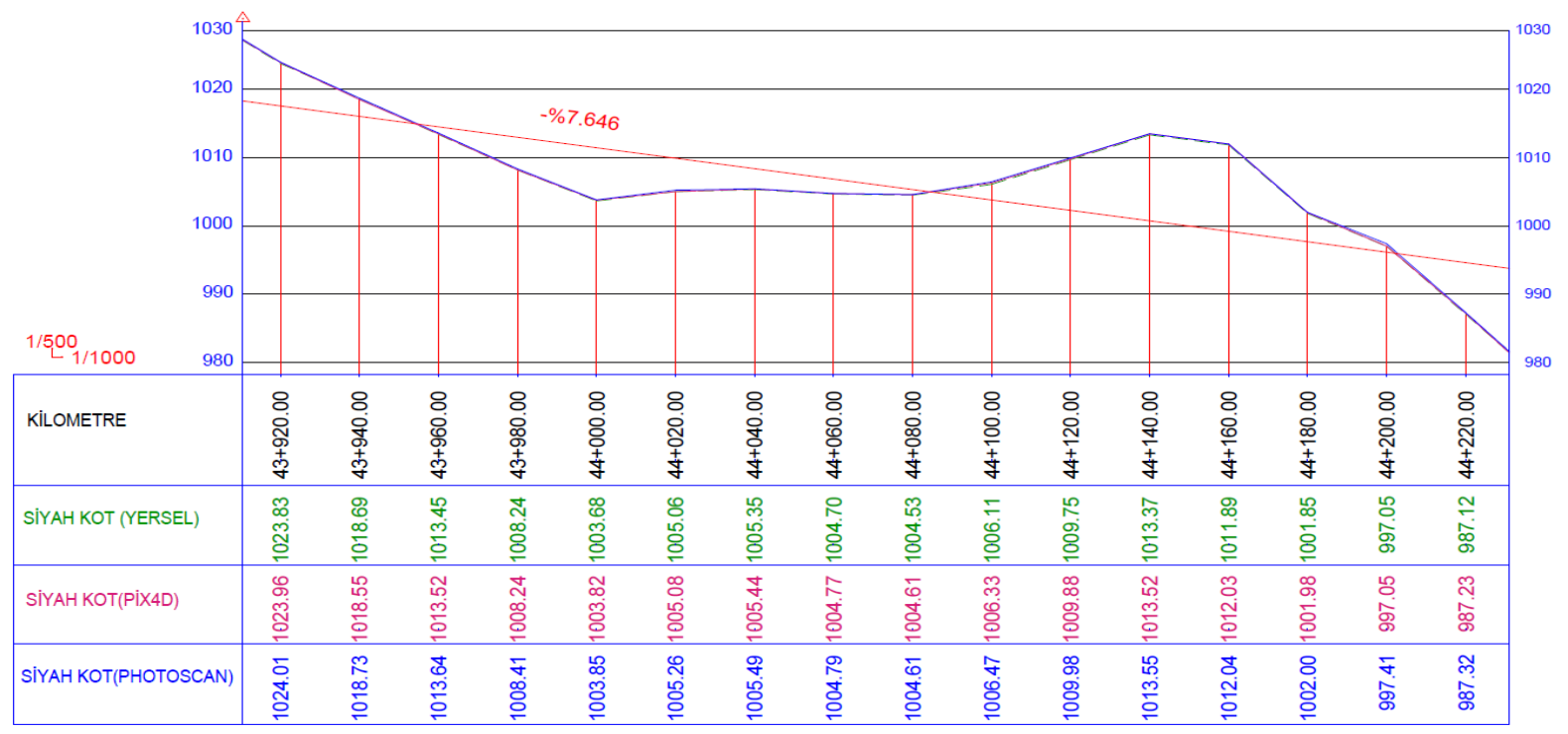

Şekil 17. 43+920.00-44+220.00 Km arası profil 


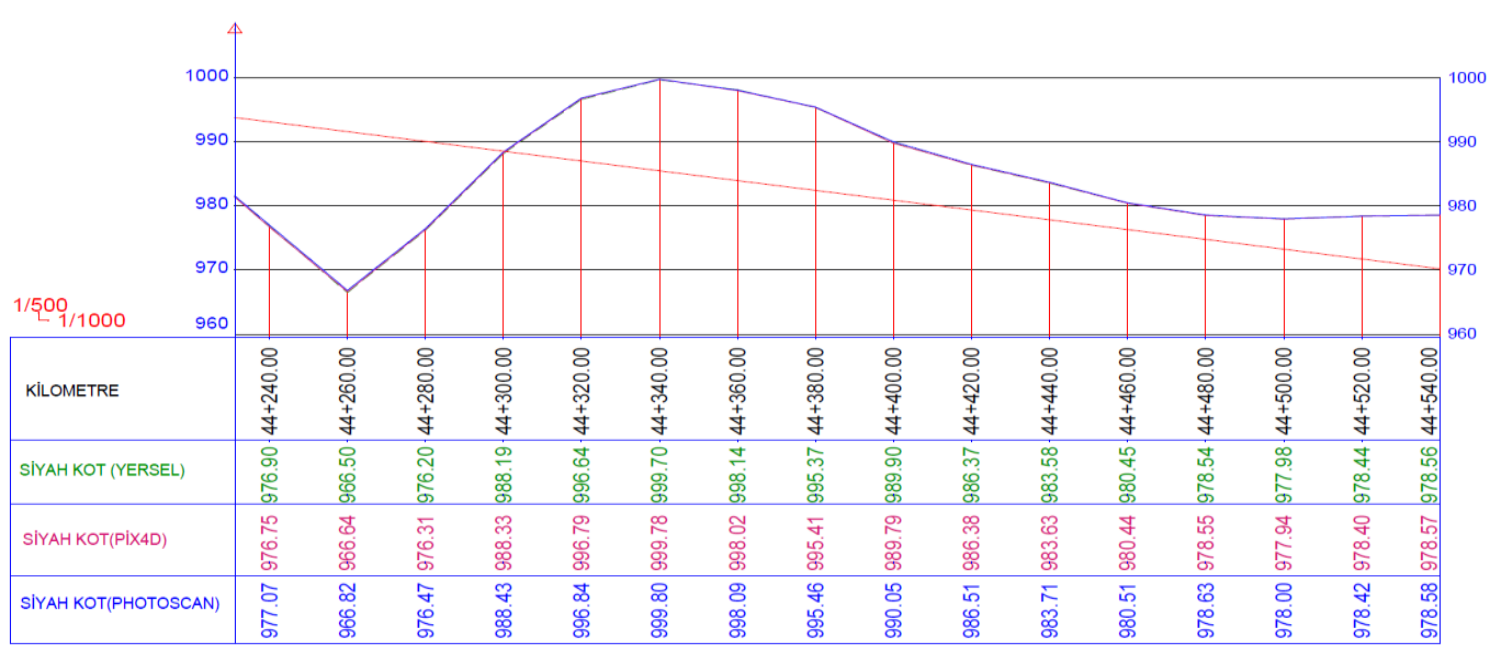

Şekil 18. $44+240.00-44+540.00 \mathrm{Km}$ aras1 profil

Calıșma alanına ilișkin yarma ve dolgu hacimleri, İHA verileri ve yersel yöntemle elde edilen veriler kullanılarak hesaplanmış ve kıyaslanmıştır. Ayrica İHA verilerinden üretilen sayısal arazi modellerinde, 1907 adet yersel noktaya karşıllk gelen noktalar seçilerek yeniden sayısal arazi modelleri oluşturulmuştur. $\mathrm{Bu}$ modellere göre toprak işi miktarları hesaplanmıştır. Ayrıca İHA görüntülerinden Pix4D yazılımıyla üretilen sayısal arazi modelinin tamamı kullanılarak toprak iși miktarları hesaplanmıştır. Toplamda dört faklı değerlendirme yapılmış olup toprak işi miktarları karşılaştırması Tablo 7'de verilmiştir.

Proje alanında yersel ve İHA yöntemiyle üretilmiş arazi modeli ile proje eksenine dik düşey düzleminin arakesitini gösterir enkesit örnekleri Şekil 19 ve 20'de gösterilmiştir.

Tablo 7. Toprak İşi miktarları karşılaştırması

\begin{tabular}{|l|l|l|l|l|}
\hline & \multicolumn{1}{|c|}{ Yersel Yöntem } & \multicolumn{1}{|c|}{$\begin{array}{c}\text { SAM Pix4D } \\
(\mathbf{1 9 0 7} \text { nokta) }\end{array}$} & $\begin{array}{c}\text { SAM PhotoScan } \\
(\mathbf{1 9 0 7} \text { nokta })\end{array}$ & \multicolumn{1}{c|}{$\begin{array}{c}\text { SAM Pix4D } \\
\text { (Tüm SAM) }\end{array}$} \\
\hline Yarma Hacmi $\left.\mathbf{( m}^{\mathbf{3}}\right)$ & 226518.366 & 227817.895 & 229977.964 & 233747.908 \\
\hline Dolgu Hacmi $\left.\mathbf{( m}^{\mathbf{3}}\right)$ & 91793.012 & 91051.575 & 90513.809 & 88587.932 \\
\hline Farklar(Yersel-Yarma) & - & 1299.529 & 3459.598 & 7229.542 \\
\hline Farklar(Yersel-Dolgu) & - & -741.437 & -1279.203 & -3205.08 \\
\hline Farklar Yüzdesi (Yarma) & - & $\% 0.6$ & $\% 1.5$ & $\% 3.2$ \\
\hline Farklar Yüzdesi(Dolgu) & - & $\% 0.8$ & $\% 1.4$ & $\% 3.5$ \\
\hline
\end{tabular}

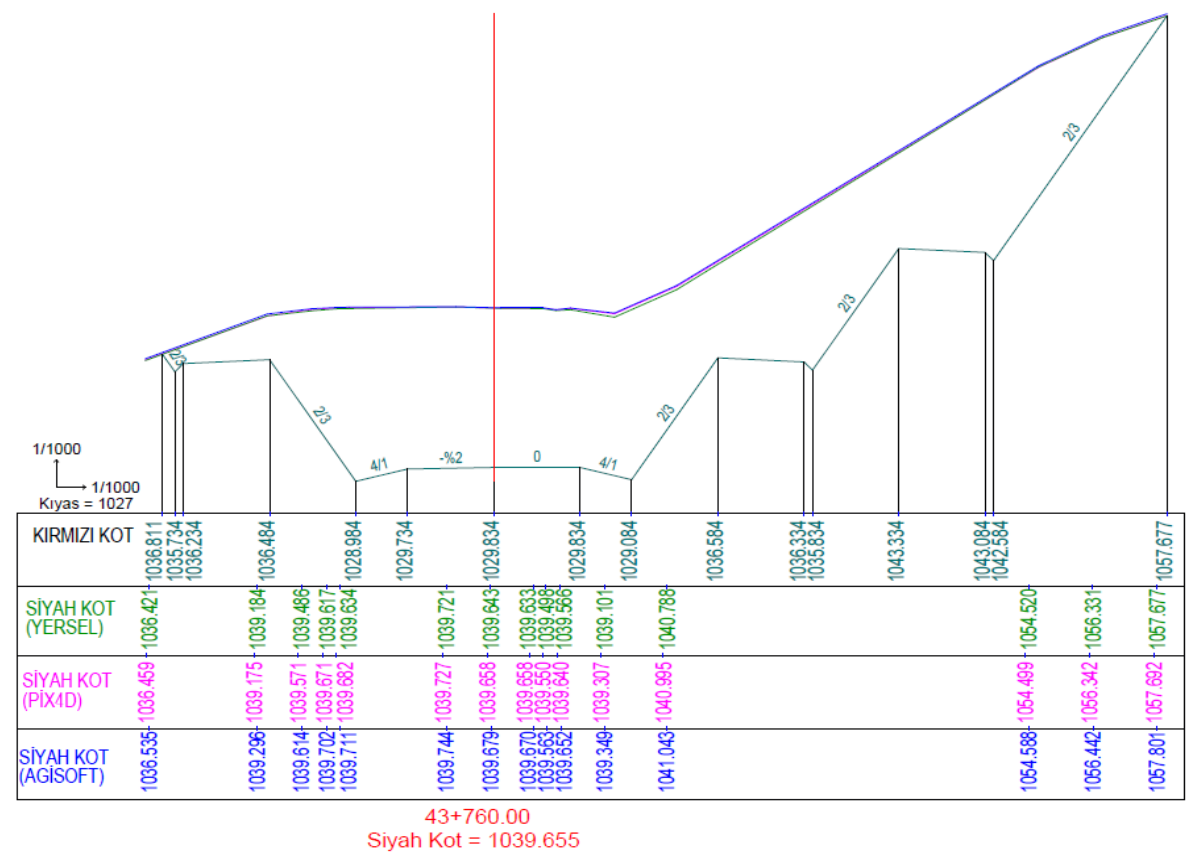

Şekil 19. 43+760.00 Kilometre enkesiti ve siyah kot görünümleri 


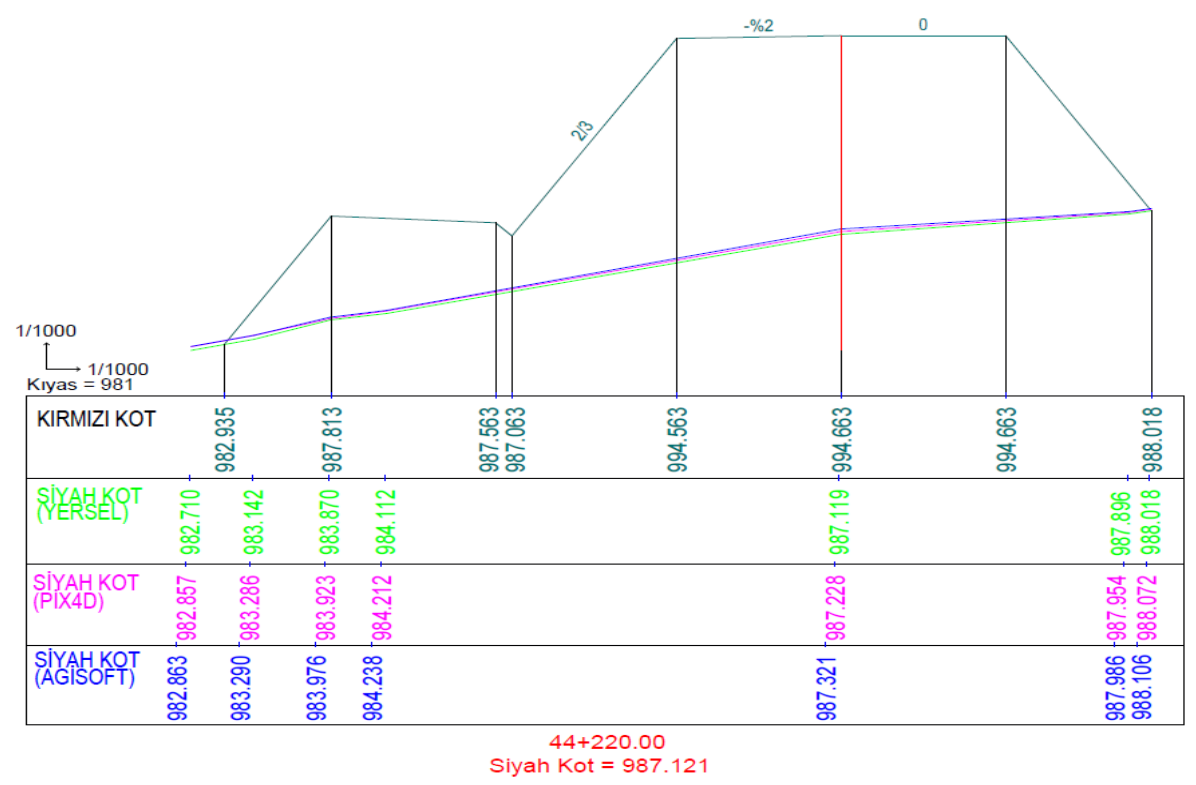

Şekil 20. 44+220.00 Kilometre enkesiti ve siyah kot görünümleri

\section{Bulgular ve Sonuçların İrdelenmesi}

İnsansız hava araçlarının ormanlık alanlarda karayolu projelerinde kullanılabilirliğini araştırmak amacıyla gerçekleştirilmiş çalışmada elde edilen sonuçlar avantaj ve dezavantajları irdelenmiştir. Çalışma alanında işaretli 10 adet noktanın konum kontrolü sonucunda elde edilen karesel ortalama hata $(\mathrm{KOH})$ değerleri incelendiğinde alçak irtifada alınan görüntülere ait hata miktarının nispeten daha az olduğu görülmüştür. Aynı yükseklikteki uçuşlar bindirme oranına göre incelendiğinde ise $\% 80$ bindirme oranında hata miktarının \%70 bindirme oranına göre daha az olduğu görülmüsşür. Agisoft PhotoScan ve Pix4D yazılımlarının kontrol sonuçları karşılaştırıldığında ise Pix4D ile elde edilen sonuçlarda farkın nispeten daha az olduğu sonucuna varılmıştır.

Yersel yöntemle elde edilen detay noktalarının yükseklik bilgileri, Pix4D ile 21 YKN ile dengelenerek üretilmiş tüm sayısal arazi modelleri ve Agisoft PhotoScan ile değerlendirilmiş doğruluğu en yüksek model ile karşılaştırılmıştır. Burada 1907 noktaya ait yükseklik verileri Autocad Civil 3D yazılımı kullanılarak sayısal arazi modelinden üretilmiştir. 1907 noktanın yükseklik verileri karşılaştırıldığında en düşük karesel ortalama hata değeri $12.9 \mathrm{~cm}$ ile Pix4D yazılımında değerlendirilmiş 100 metre yükseklikten $\% 80$ bindirme oran1 ile üretilmiş görüntülere aittir (Tablo 6). Agisoft PhotoScan ile değerlendirilmiş aynı yükseklik ve bindirme oranına sahip görüntülerden elde edilen sonuç ise $15.9 \mathrm{~cm}$ ile en yüksek hatayı vermiştir. Agisoft
PhotoScan yazılımında 100 metre yükseklikten $\% 80$ bindirme oranında dengelenen görüntülerin yer örnekleme aralığı (YÖA) değeri 2.75 $\mathrm{cm} /$ piksel iken Pix4D ile $2.80 \mathrm{~cm} /$ piksel olarak elde edilmiştir. Ayrıca Pix4D ile üretilen nokta say1s1 55780927 iken Agisoft PhotoScan yazilıminda 50756077 adettir. Buradan Pix4D ile arazinin daha detaylı temsil edildiği sonucuna ulaşmak mümkündür. Toprak işi miktarları karşılaştırılarak farkların yüzdeleri değerlendirildiğinde Pix4D yazılımı ile üretilen sayısal arazi modeli sonuçlarının yersel yönteme daha yakın olduğu görülmüştür. Yersel olarak üretilen noktaların Pix4D'de üretilen nokta bulutundaki karşıllı̆ı olan 1907 nokta ile sayısal arazi modeli oluşturulmuş ve buna göre yarma hacminde $\% 0.6$, dolgu hacminde $\% 0.8$ oranında fark olduğu görülmüştür. Pix4D'de üretilen nokta bulutunun tamamı kullanılarak oluşturulan sayısal arazi modeline göre yarma hacminde \%3.2, dolgu hacminde $\% 3.5$ oranında fark olduğu görülmüştür. Aynı yazılım kullanılarak iki farklı oran elde edilmiştir. Bunun nedeni olarak da yersel yönteme kıyasla arazi yapısının insansız hava arac1 yöntemiyle daha detaylı tasvir edilmesi görülmektedir.

Sonuçlar benzer çalışmalarla kıyaslandığında; bir karayolu projesinde düz bir arazi yapısına sahip alanda gerçekleştirilmiş çalışmada kazı hacmindeki fark \%0.998, dolgu hacmindeki fark \%0.997 olarak bulunmuştur (Erdoğan, 2016). Dalgalı arazi yapısına sahip alanda gerçekleştirilmiş bir diğer çalışmada ise kazı hacmindeki fark \%11.3, dolgu hacmindeki fark \%-1.1 olarak bulunmuştur (Tercan, 2017). Bir 
başka uygulamada karayolu çalışma alanında 3 adet toprak yığınına ait hacimler incelenerek farklılıkların \% 8-16 arasında olduğu görülmüştür (Siebert ve Teizer, 2014). Bu çalışma ise ormanlık ve dağlık yapıda bir alanda gerçekleştirilmiş olup yarma hacminde \%3.2, dolgu hacminde \%3.5 oranında fark olduğu görülmüştür. Bu çalışmada hacim miktarları karşılaştırmasında diğerlerinden farklı bir yöntem daha izlenmiştir. Yersel yöntemle üretilen 1907 noktanın yatay konumuna karşılık gelen yükseklik değerleri İHA görüntülerinden üretilen sayısal yükseklik modelinden alınmış ve kıyaslanmıştır. Ayrıca bu konum bilgileri ile yeni bir sayisal yükseklik modeli oluşturulmuş ve hacim hesab1 gerçekleştirilmiştir. Yapılan karşılaştırmalar sonucunda insansız hava araçlarının yersel yöntemle veri üretimine alternatif olabileceği düşünülmektedir.

Çalışma incelendiğinde İHA verileri ile elde edilen sonuçların yersel yöntemle benzer olduğu görülmektedir. Sonuçlar arasındaki farklar; yazılımlarda kullanılan algoritma ve yöntemlerden kaynaklı olabileceği gibi yer kontrol noktalarının işaretlenmesi, elle sınıflandırma işlemleri sirasında operatör kaynaklı da olabilmektedir. Toprak işi miktarlarının karşılaştırılmasında temel altlik sayısal arazi modelidir. Uygulamada kullanılan yazılımlar sayısal arazi modelini sınıflandırılmış nokta bulutunu kullanarak oluşturmaktadır. Menteşoğlu ve İnan (2016)'a göre; insansız hava araçları kullanılarak elde edilen nokta bulutu verisinin gerekli siniflandirma çalışmalarından sonra üretilen sayısal yükseklik modeli (SYM); söz konu alana ilişkin konum ve yükseklik bilgisini yüksek doğrulukta içermekte ve arazi üzerindeki orman, bitki örtüsü, binalar gibi tüm detayları tanımlamaya yeterli 3 boyutlu modellemeye olanak vermektedir. Ayrica nokta bulutunun değerlendirilmesiyle sadece çıplak yer yüzeyini tanımlayan, eğim, bak1 ve kabartma haritası gibi analizlere olanak veren Sayısal Arazi Modeli de (SAM) üretilebilmektedir. Buradan yola çıkarak nokta bulutunda bitki örtüsünün sinıflandırılmasının sayısal yükseklik modelinin doğruluğuna etki ettiğini söylemek mümkündür. Çalışma alanının ormanlık bir yapıya sahip olması nedeniyle sınıflandırma işlemi önem taşımaktadır. Yapılan çalışmada Pix4D ve Agisoft PhotoScan yazılımlarında sınıflandırma işlemi otomatik olarak yapılmış olup ayrıca Agisoft PhotoScan yazılıminda siniflandırma parametreleri manuel olarak girilmiştir. Agisoft PhotoScan yazılımı otomatik sinıflandırmada kullanılan parametreler açısından kullanıcıya esneklik sağlamaktadır. Toprak işi miktarları karşılaştırıldığında Pix4D yazılımı ile elde edilen sonuçların yersel yöntem ile daha yakın olduğu sonucuna varılmıştır. Bununla birlikte üretilen verinin doğruluğu, kullanılan İHA ve kamera türüne, değerlendirme yazılımına, kullanılan algoritma ve yöntemlere, iklim ve atmosferik koşullara, çalışma alanının yapısına ve değerlendiren operatörünün yeteneğine bağlı olarak değişebilmektedir. Ayrıca İHA sistemlerinin uçuş süresinin sinırlı olması, hava koşullarından etkilenmesi, geniş uygulama alanlarında veri boyutunun fazla olması görüntü değerlendirme ve saklama problemi İHA kullanımında dezavantaj sağlamaktadır. Uygulamada elde edilen sonuçlar doğrultusunda İHA verisi kullanımının, arazi temsilinin önem taşıdığı karayolu projelerinde yersel yöntemlere alternatif, ekonomik, hızlı ve güvenilir bir yöntem olabileceği ortaya çıkmaktadır.

\section{Katkı Belirtme}

Bu çalışma, Yağmur FiDANCI'nın yüksek lisans tezinden yapılmıştır.

\section{Kaynaklar}

Akgül, M., Yurtseven, H., Demir, M., Akay, A.E., Gülci, S. ve Öztürk, T., 2016. İnsansız Hava Araçları İle Yüksek Hassasiyette Sayısal Yükseklik Modeli Üretimi Ve Ormancilıkta Kullanım Olanakları. Journal of the Faculty of Forestry Istanbul University, 66(1), 104-118.

Avdan, U., Gülşen, F.F., Ergincan, F. ve , Çömert, R., 2014. Arkeolojik Alanlarda Taş Planlarının Çıkarılmasında İnsansız Hava Araçlarının Kullanılmas1 (Anavarza Örneği). 7. Mühendislik Ölçmeleri Sempozyumu, 15-17 Ekim 2014, Hitit Üniversitesi, Çorum.

Carvajal, F., Agüera, F. ve Pérez, M.,2011. Surveying A Land slide In A Road Embankment Using Unmanned Aerial Vehicle Photogrammetry. International Archives of the Photogrammetry, Remote Sensing and Spatial Information Sciences, Vol. XXXVIII-1/C22 UAV-g, Conference on Unmanned Aerial Vehicle in Geomatics, Zurich, Switzerland, 2011

Erdoğan, A., 2016. Şeritvari Haritaların İnsansız Hava Araçları İle Üretimi. Yüksek Lisans Tezi, Selçuk Üniversitesi, Fen Bilimleri Enstitüsü. Konya,48s.

Gürbüz, M. F. ve Türker, M.,2017. Çok Yüksek Çözünürlüklü İHA Görüntülerinden Otomatik Ağaç Tespiti. Türkiye Ulusal Fotogrametri ve Uzaktan Algılama Birliği IX. Teknik Sempozyumu (TUFUAB2017),27-29 Nisan 2017, Afyonkarahisar. 
Haarbrink, R.B. ve Eisenbeiss, H., 2008. Accurate Dsm Production From Unmanned Helicopter Systems. The International Archives of the Photogrammetry Remote Sensing and Spatial Information Sciences,Vol. XXXVII. Part B1. Beijing.

Li, Z.L., 1990. Sampling Strategyand Accuracy Assessment for Digital Terrain Modelling. PhDthesis, The University of Glasgow. Glasgow.

Menteşoğlu, B. E. ve İnan, M.,2016. İnsansız Hava Araçlarının (İHA) Ormancılık Uygulamalarında Kullanımı. 6. Uzaktan Algilama ve CBS Sempozyumu, 5-7 Ekim 2016, Adana.

Miller, C. ve Laflamme, R., 1958. The Digital Terrain Model-Theory And Applications. Photogrammetric Engineering, Volume 24,Pages433-442.

Siebert, S. Ve Teizer, J., 2014. Mobile 3D Mapping For Surveying Earthwork Using An Unmanned
Aerial Vehicle (UAV). Automation in Construction, Volume 41, May 2014,Pages 114.

Tercan, E., 2017. Karayolu Projelerinde İnsansız Hava Aracı ile Üretilen Sayısal Arazi Modelinin Değerlendirilmesi: Bucak-Kocaaliler Yolu Örneği. Mehmet Akif Ersoy Üniversitesi Fen Bilimleri Enstitüsü Dergisi (MAKÜ FEBED), cilt 8 , sayı 2 , sayfa $172-183$.

Uysal, M. ve Toprak, A.S., 2015. İnsansiz Hava Araçları İle Sayısal Arazi Modeli Üretimi. Türkiye Ulusal Fotogrametri ve Uzaktan Algılama Birliği VIII. Teknik Sempozyumu (TUFUAB 2015), 21-23 Mayıs 2015, Konya.

Yılmaz, V., Akar, A., Akar, Ö., Güngör, O., Karslı, F. ve Gökalp, E.,2013. İnsansız Hava Aracı İle Üretilen Ortofoto Haritalarda Doğruluk Analizi. Türkiye Ulusal Fotogrametri ve Uzaktan Algılama Birliği VII. Teknik Sempozyumu (TUFUAB 2013), 23-25 Mayıs 2013, KTÜ, Trabzon. 